\title{
Does professional background influence in temporomandibular joint tissues evaluation by magnetic resonance imaging?
}

\author{
Juliana Andréa Corrêa Travessas, Mathias Pante Fontana, Priscila Fernanda Da Silveira, Mariana Boessio Vizzotto, \\ Heraldo Luis Dias Da Silveira', Nadia Assein Arús ${ }^{1}$ \\ Department of Surgery and Orthopedics, School of Dentistry, Federal University of Rio Grande do Sul, 'Department of Surgery and \\ Orthopedics, Federal University of Rio Grande do Sul, Porto Alegre, RS, Brazil
}

\section{A B S T R A C T}

Context: Imaging examinations afford more consistent details than clinical evaluation in the investigation process and make the differential diagnosis of temporomandibular joint (TMJ) disorders (TMDs) easier. Aims: This study aimed to check agreement among professionals from different fields of work evaluating TMDs using magnetic resonance imaging (MRI) and based on ten diagnoses criteria: Position, shape and recapture of joint disk, joint mobility, degenerative changes, bone changes, condyle position, effusion, intramedullary edema, and avascular necrosis. Methods: An oral and maxillofacial radiologist, a medical radiologist, and a dental surgeon specialized in TMD and orofacial pain interpreted $152 \mathrm{MRI}$ taken from 76 patients. A scenario simulating daily activities was devised, which neither calibration nor discussion of criteria was assessed. Interobserver agreement was measured using the Kappa coefficient. Results: Poor agreement was observed in avascular necrosis; a slight agreement was recorded in form and position of the joint disk, condyle position, effusion; fair agreement in TMJ mobility and disk recapture; moderate to almost perfect agreement in condylar changes, degenerative changes, and intramedullary edema. Conclusion: Professionals from different areas that interpret TMJ disorders using MRI did not agree on the diagnoses, especially for the soft-tissue changes.

Key words: Diagnostic imaging, magnetic resonance imaging, observer variation, temporomandibular joint

\section{INTRODUCTION}

The temporomandibular joint (TMJ) poses challenges in the therapeutics and diagnosis due to its anatomical and physiological complexities. TMJ pain and dysfunction are common occurrences and may result from a variety of etiological factors, both of traumatic and nontraumatic nature, categorized as muscle dysfunctions and arthrogenic dysfunctions. The syndrome comprising the symptoms produced by these factors bears some resemblance to

\begin{tabular}{|l|l|}
\hline \multicolumn{2}{|c|}{ Access this article online } \\
\hline Quick Response Code: & \multirow{2}{*}{ Website: } \\
\hline & www.joomr.org \\
\cline { 2 - 2 } & DOI: \\
\hline
\end{tabular}

muscle and arthrogenic conditions and is collectively called TMJ disorder (TMD). ${ }^{[1,2]}$

While clinical evaluation methods are loosely based on inspection, palpation, and performance tests, imaging examinations afford more consistent details in the investigation process and make the differential diagnosis of TMD easier. More specifically, due to its high-resolution capabilities and efficiency, with no side effects, magnetic

This is an open access article distributed under the terms of the Creative Commons Attribution-NonCommercial-ShareAlike 3.0 License, which allows others to remix, tweak, and build upon the work non-commercially, as long as the author is credited and the new creations are licensed under the identical terms.

For reprints contact: reprints@medknow.com

Cite this article as: Travessas JA, Fontana MP, Da Silveira PF, Vizzotto $\mathrm{MB}$, Da Silveira HL, Arús NA. Does professional background influence in temporomandibular joint tissues evaluation by magnetic resonance imaging? J Oral Maxillofac Radiol 2018;6:9-13.

Address for correspondence: Prof. Juliana Andréa Corrêa Travessas, Rua Ramiro Barcelos, 2492 CEP 90035-003 Porto Alegre, RS, Brazil. E-mail: jutravessas@terra.com.br 
Travessas, et al.: Temporomandibular joint by MRI

resonance imaging (MRI) is widely employed for that purpose. ${ }^{[3,4]}$ MRIs assessment is the complementary tool of choice in the diagnosis of abnormalities of TMJ soft tissues $^{\left[{ }^{[}\right]}$and is taken as diagnostic gold standard in the evaluation of articular disk position. ${ }^{[6]}$ The results of a meta-analysis indicated that, compared to MRI, clinical evaluation has poor validity diagnosing disk displacement with or without reduction. Besides that, MRI should be an option when the results could change treatment protocol. ${ }^{[7]}$

However, two systematic reviews on diagnostic efficacy showed inconsistent results to confirm the real benefits of MRI. ${ }^{[8,9]}$ One found impossible to reach any conclusion relating MRI examinations and its influence in patient's treatment. ${ }^{[8]}$ The other systematic review reported low evidence on benefits using MR or computed tomography (CT) images on the TMD diagnosis and patient treatment. ${ }^{[0]}$ As patient benefit is uncertain, clear referring criteria for CT and MRI, based on scientific evidence, must be established. ${ }^{[10]}$

The current standard used to interpret MRI of TMJ involves a subjective evaluation and depends on the knowledge of the observer about the joint structures and on how far the observer is acquainted with the morphology, function, and pathophysiology of TMJ. In this sense, together with accuracy in diagnosis, the performance of the observer is an important variable in reliable imaging interpretation. ${ }^{[1]}$ Diagnosis criteria for disk joint position, ${ }^{[12,13]}$ condyle position, ${ }^{[14]}$ and morphology of the joint disk ${ }^{[15,16]}$ have been described in the specialized literature to bridge the gap of effective communication across professionals and to afford appropriate imaging.

A study comparing MRIs of TMJ showed significantly better image quality as well as visibility and delineation of clinically relevant anatomical structures obtained at 3.0 $\mathrm{T}$ than at $1.5 \mathrm{~T}$. In addition, the interrater reliability ranged from "substantial agreement" to "almost perfect agreement." $[17]$

Several approaches have addressed the issues around the reliability of TMJ MRI, which include the adoption of preestablished criteria, ${ }^{[11,18-20]}$ observer calibration, ${ }^{[21]}$ the use of techniques to quantify joint disk position, ${ }^{[22]}$ and digital tools. ${ }^{[23]}$ These methods went no further than producing a moderate agreement in interpretation. However, in a scenario in which radiology clinics is simulated, in which professionals come from different educational backgrounds and do not go through calibration procedures, together with the fact that they work with no preestablished interpretation criteria, low inter- and intraobserver reproducibility has been reported. ${ }^{[24]}$
This study analyzed agreement in MRI of the TMJ interpretation among professionals with different backgrounds based on ten criteria: position, form, and recapture of the TMJ disk, joint mobility, degenerative changes, bone changes, condyle position, effusion, intramedullary edema and avascular necrosis.

\section{Methods}

MRI examinations of 76 adult patients of both genders were used. These images were part of a 2-year record of files kept by a specialized medical radiology service. The radiology service provided written consent to use the images in this study. Ethical Committee of the college approved this study (n. 36,729), Federal University of Rio Grande do Sul, RS, Brazil. The study was performed in full accordance with the World Medical Association Declaration of Helsinki. All participants involved in the study were verbally consented to participate in the study. This consent procedure was following the ethical committee instructions. The examinations generated 152 videos, accounting for imaging of both the right and left TMJ of each examination. Images were acquired over "habitual occlusion" and "maximum mouth opening" positions using a 0.5 T MRI unit (Intera, Philips Medical System ${ }^{\mathrm{TM}}$ ). Both sides of the TMJ were recorded simultaneously using a specific coil for TMJ anatomy. All T1- and T2-weighted parasagittal and coronal sections of joints were converted into video files and individually inspected. Three professionals from different educational backgrounds: an oral and maxillofacial radiologist working more than a decade with MRI (observer 1); a medical radiologist with 5 years of experience to interpret MRI of TMJ (observer 2); and a dental surgeon specialized in TMD and orofacial pain, with 5 years of experience in analyzing MRI (observer 3) interpreted the images and answered a questionnaire that addressed the changes and classifications to be used:

a. Presence or absence of condylar bone change

b. Changes in joint disk shape (normal, round, elongated, biconvex, and thickening of the posterior disk attachment)

c. Condyle position (centric, intruded, extruded, posteroinferior, and anteroinferior)

d. Joint mobility (normal, hypo- or hypermobility)

e. Presence or absence of degenerative changes

f. Joint disk position (normal, complete anterior displacement, partial anterior displacement laterally, partial anterior displacement medially, complete lateral displacement, complete medial displacement, posterior displacement, and undetermined displacement)

g. Joint disk recapture (with recapture, without recapture, and undetected TMJ disk anterior displacement) 
Travessas, et al.: Temporomandibular joint by MRI

h. Effusion (absence, supradisk, infradisk, and bicompartmental)

i. Presence or absence of intramedullary edema

j. Presence or absence of avascular necrosis.

The observers were instructed to evaluate the images using a desk computer, with a minimal of 15 inches, in a room with reduced light. The professionals could study the cases, and there was not any time limit. Agreement of TMD interpretation was assessed using the Kappa coefficient. Data were analyzed using the SPSS software version 15.0 for Windows (SPSS, Chicago, Il, USA). Kappa values were interpreted based on previously described criteria: $<0.00$ poor; $0.00-0.20$, slight; $0.21-0.40$, fair; $0.41-0.60$ moderate; 0.61-0.80, substantial; and 0.81-1.00, almost perfect agreement. ${ }^{[25]}$

\section{Results}

Interobserver agreement was assessed across the three professionals, two by two, generating four Kappa values for each criterion analyzed [Table 1]. Kappa results among the three observers showed poor agreement in avascular necrosis; slight in the assessment of joint disk shape, condyle position in the articular cavity, joint disk position, and presence or absence of effusion; fair agreement was detected on TMJ disk mobility and disk recapture; moderate agreement was observed concerning the presence or absence of condyle bone change, and intramedullary bone edema and substantial agreement were noticed on the presence or absence of degenerative changes. It was detected that observers 1 and 2 (the dental surgeon specialized in radiology and the MD radiologist) presented the lowest overall mean of the agreement, while observers 2 and 3 (MD radiologist and dental surgeon specialized in TMD and orofacial pain) showed the highest mean.

\section{Discussion}

MRI is the technique of choice for the assessment of TMJ disorders in soft tissues ${ }^{[6]}$ and has gradually replaced arthrography to evaluate joint disk alterations. ${ }^{\left[{ }^{[}\right]}$According to a study that estimated the TMD diagnosis in MRI among four professionals, the authors concluded that diagnosis made by a single examiner should not be accepted as a gold standard. ${ }^{[26]}$ Similar to previously published researchers, ${ }^{[24,26]}$ the present study was an effort to simulate everyday situations in the practice of TMD diagnosis, relying on the particular interpretation of findings by the respective professionals, who did not use specific supporting tools for TMD analysis, as suggested by Provenzano et al..$^{[23]}$ Considering that the image acquisition method has been proven acceptable and is widely used in clinical practice, ${ }^{[6,27]}$ a previous study that compared nine observers, of whom three were oral and maxillofacial radiologist, three were MD radiologist and three were dental surgeons specialized in TMD and orofacial pain also reported Kappa values below 0.6 for most of the changes in TMJ, even within observers from the same background. ${ }^{[2]}$ It is possible to suggest that individual interpretations in MR, despite diverse educational background, remain as a challenge in TMJ imaging diagnosis.

The results of this study show slight to a fair interobserver agreement on joint disk shape, position and on the presence of effusion, which are changes that affect soft tissues or liquid. For the investigation on hard tissues, the observers reached moderate to almost perfect agreement.

The selection of experienced professionals in the design of such studies ${ }^{[21,24,26,28]}$ gives no pledges that good interobserver agreement will be achieved. In addition, the studies may adopt different categories of TMJ disorders, a variable that adds confusion and affects final research results. Based on these results, we can advise that the observers seem to assume different criteria for normality and pathology in TMJ assessing MRI. Furthermore, it may be hypothesized that the quality of images, which were acquired in a $0.5 \mathrm{~T}$ device, could affect the interpretation. Evaluating 1.5 T MRI, Schmitter et al. observed that a higher interobserver agreement could be achieved by selecting the best-quality MRIs. ${ }^{[29]}$ However, some other

Table I: Interobserver agreement in the interpretation of temporomandibular joint disorders using magnetic resonance imaging assessed by kappa coefficient

\begin{tabular}{lccccccccccc} 
& \multicolumn{9}{c}{} & \multicolumn{8}{c}{ Criteria used for diagnoses of TMD using MRI } \\
\cline { 2 - 11 } & A & B & C & D & E & F & G & H & I & J & Mean \\
All three (I, 2 and 3) & $0.567 \mid$ & 0.1244 & 0.0265 & 0.2554 & 0.6007 & 0.0370 & 0.2136 & 0.0658 & 0.5584 & -0.0178 \\
Observers I versus 2 & 0.5088 & 0.1477 & 0.0293 & 0.2195 & 0.5077 & 0.0436 & 0.1674 & 0.0071 & 0.5973 & 0.0000 & 0.2228 \\
Observers I versus 3 & 0.6646 & 0.1553 & 0.0669 & 0.2916 & 0.5176 & 0.0197 & 0.2137 & 0.2632 & 0.5487 & 0.0000 & 0.2741 \\
Observers 2 versus 3 & 0.5167 & 0.2298 & 0.3290 & 0.5057 & 0.8007 & 0.3308 & 0.4917 & 0.0865 & 0.3700 & 0.1112 & 0.3772 \\
\hline
\end{tabular}

Observers: I: Dental surgeon specialized in radiology; 2: Medical doctor radiologist MD; 3: Dental surgeon specialized in TMD and orofacial pain; Criteria: A: Condylar bone change; B: Changes in joint disk shape; C: Condylar position; D: Joint mobility; E: Degenerative changes; F: Joint disk position; G: Joint disk recapture; H: Effusion; I: Intramedullary edema; J:Avascular necrosis; MRI: Magnetic resonance imaging;TMD:Temporomandibular joint disorders 
Travessas, et al.: Temporomandibular joint by MRI

studies $^{[24,26,28]}$ carried out based on 1.5 T MRI similarly reported poor agreement diagnosing some changes in TMJ.

The present study informed observers about diagnosis criteria using an electronic questionnaire, in which each professional should identify the change revealed by the image. No previous discussion was held as to these changes since the main objective of the study was to analyze the issues faced in everyday practice. In this sense, each observer evaluated images according to their own experience. Studies that promoted a prior discussion of TMD, ${ }^{[11,12,18]}$ that included calibration methods, ${ }^{[2]}$ that used methods free of subjectiveness, ${ }^{[22]}$ or implemented supporting tools ${ }^{[23]}$ reported more suitable results for diagnosis agreement. It became clear that, apart from the need to define criteria to assess TMD by MRI, educational practices also require adaptations aiming to standardize terminologies and classifications that afford more congruent, agreement diagnosis findings among observers. This situation led to the development of a digital learning object (DLO) that selected a hundred images from this study, by a consensus among the three professionals on the diagnosis and good visual quality. This DLO was tested through improved knowledge on TMD in MRI diagnostic. ${ }^{[3]}$

\section{Conclusion}

It is possible to assume that professionals who interpret TMD using MRI, with diverse educational backgrounds, did not share the same concepts, resulting in different diagnoses, especially when assessing soft tissues, which MRI is considered the best choice in imaging diagnosis.

\section{Financial support and sponsorship}

Nil.

\section{Conflicts of interest}

There are no conflicts of interest.

\section{References}

1. Neville DA. Oral and Maxillofacial Pathology. $3^{\text {rd }}$ ed. Philadelphia: Saunders/Elsevier; 2009.

2. Isberg A. Temporomandibular Joint Dysfunction: A Practitioner's Guide. Oxford: Isis Medical Media; 2001.

3. Vogl TJ, Balzer J, Mack M, Steger W. Differential Diagnosis in Head and Neck Imaging. Stuttgart: Thieme; 1999.

4. Tvrdy P. Methods of imaging in the diagnosis of temporomandibular joint disorders. Biomed Pap Med Fac Univ Palacky Olomouc Czech Repub 2007;151:133-6.

5. Ferreira LA, Grossmann E, Januzzi E, de Paula MV, Carvalho AC. Diagnosis of temporomandibular joint disorders: Indication of imaging exams. Braz J Otorhinolaryngol 2016;82:341-52.
6. Poveda Roda R, Díaz FernándezJM, Hernández Bazán S, Jiménez Soriano Y, Margaix M, Sarrión G, et al. A review of temporomandibular joint disease (TMJD). Part II: Clinical and radiological semiology. Morbidity processes. Med Oral Patol Oral Cir Bucal 2008;13:E102-9.

7. Pupo YM, Pantoja LL, Veiga FF, Stechman-Neto J, Zwir LF, Farago PV, et al. Diagnostic validity of clinical protocols to assess temporomandibular disk displacement disorders: A meta-analysis. Oral Surg Oral Med Oral Pathol Oral Radiol 2016;122:572-86.

8. Limchaichana N, Petersson A, Rohlin M. The efficacy of magnetic resonance imaging in the diagnosis of degenerative and inflammatory temporomandibular joint disorders: A systematic literature review. Oral Surg Oral Med Oral Pathol Oral Radiol Endod 2006;102:521-36.

9. Ribeiro-Rotta RF, Marques KD, Pacheco MJ, Leles CR. Do computed tomography and magnetic resonance imaging add to temporomandibular joint disorder treatment? A systematic review of diagnostic efficacy. J Oral Rehabil 2011;38:120-35.

10. Petersson A. What you can and cannot see in TMJ imaging - An overview related to the RDC/TMD diagnostic system. J Oral Rehabil 2010;37:771-8.

11. Tasaki MM, Westesson PL, Raubertas RF. Observer variation in interpretation of magnetic resonance images of the temporomandibular joint. Oral Surg Oral Med Oral Pathol 1993;76:231-4.

12. Tasaki MM, Westesson PL, Isberg AM, Ren YF, Tallents RH. Classification and prevalence of temporomandibular joint disk displacement in patients and symptom-free volunteers. Am J Orthod Dentofacial Orthop 1996; 109:249-62.

13. Whyte AM, McNamara D, Rosenberg I, Whyte AW. Magnetic resonance imaging in the evaluation of temporomandibular joint disc displacement - A review of 144 cases. Int J Oral Maxillofac Surg 2006;35:696-703.

14. Kurita H, Ohtsuka A, Kobayashi H, Kurashina K. A study of the relationship between the position of the condylar head and displacement of the temporomandibular joint disk. Dentomaxillofac Radiol 2001;30:162-5.

15. Milano V, Desiate A, Bellino R, Garofalo T. Magnetic resonance imaging of temporomandibular disorders: Classification, prevalence and interpretation of disc displacement and deformation. Dentomaxillofac Radiol 2000;29:352-61.

16. Taşkaya-Yilmaz N, Oğütcen-Toller M. Magnetic resonance imaging evaluation of temporomandibular joint disc deformities in relation to type of disc displacement. J Oral Maxillofac Surg 2001;59:860-5.

17. Manoliu A, Spinner G, Wyss M, Erni S, Ettlin DA, Nanz D, et al. Quantitative and qualitative comparison of MR imaging of the temporomandibular joint at 1.5 and $3.0 \mathrm{~T}$ using an optimized high-resolution protocol. Dentomaxillofac Radiol 2016;45:20150240.

18. Nebbe B, Brooks SL, Hatcher D, Hollender LG, Prasad NG, Major PW, et al. Magnetic resonance imaging of the temporomandibular joint: Interobserver agreement in subjective classification of disk status. Oral Surg Oral Med Oral Pathol Oral Radiol Endod 2000;90:102-7.

19. Ahmad M, Hollender L, Anderson Q, Kartha K, Ohrbach R, Truelove EL, et al. Research diagnostic criteria for temporomandibular disorders (RDC/TMD): Development of image analysis criteria and examiner reliability for image analysis. Oral Surg Oral Med Oral Pathol Oral Radiol Endod 2009;107:844-60.

20. Hellén-Halme K, Hollender L, Janda M, Petersson A. Web-based calibration of observers using MRI of the temporomandibular joint. Dentomaxillofac Radiol 2012;41:656-61.

21. Orsini MG, Terada S, Kuboki T, Matsuka Y, Yamashita A. The influence of observer calibration in temporomandibular joint magnetic resonance imaging diagnosis. Oral Surg Oral Med Oral Pathol Oral Radiol Endod 1997;84:82-7.

22. Nebbe B, Brooks SL, Hatcher D, Hollender LG, Prasad NG, Major PW, et al. Interobserver reliability in quantitative MRI assessment of temporomandibular joint disk status. Oral Surg Oral Med Oral Pathol 
Travessas, et al.: Temporomandibular joint by MRI

Oral Radiol Endod 1998;86:746-50.

23. Provenzano Mde M, Chilvarquer I, Fenyo-Pereira M. How should the articular disk position be analyzed? J Oral Maxillofac Surg 2012;70:1534-9.

24. Butzke KW, Batista Chaves KD, Dias da Silveira HE, Dias da Silveira HL. Evaluation of the reproducibility in the interpretation of magnetic resonance images of the temporomandibular joint. Dentomaxillofac Radiol 2010;39:157-61.

25. Landis JR, Koch GG. The measurement of observer agreement for categorical data. Biometrics 1977;33:159-74.

26. Widmalm SE, Brooks SL, Sano T, Upton LG, McKay DC. Limitation of the diagnostic value of MR images for diagnosing temporomandibular joint disorders. Dentomaxillofac Radiol 2006;35:334-8.
27. Westesson PL. Reliability and validity of imaging diagnosis of temporomandibular joint disorder. Adv Dent Res 1993;7:137-51.

28. Bisi M, Teixeira ER, Chaves KD, Silveira HE, Grossi ML. Influence of the patient's clinical information on the diagnostic reproducibility and accuracy of MRI scans of temporomandibular joint pathologies. Int J Prosthodont 2014;27:245-9.

29. Schmitter M, Kress B, Hähnel S, Rammelsberg P. The effect of quality of temporomandibular joint MR images on interrater agreement. Dentomaxillofac Radiol 2004;33:253-8.

30. Arús NA, da Silva ÁM, Duarte R, da Silveira PF, Vizzotto MB, da Silveira HLD, et al. Teaching dental students to understand the temporomandibular joint using MRI: Comparison of conventional and digital learning methods. J Dent Educ 2017;81:752-8. 